\title{
Popularity of sleep disordered breathing in childhood: an analysis of worldwide search using Google Trends
}

\author{
Marco Zaffanello ${ }^{1}$, Giuseppe Lippi ${ }^{2},{\text { Nazzarena } \text { Arman }^{3} \text {, Michele Piazza }}^{1}$, Laura Tenero ${ }^{1}$, Giorgio Piacentini ${ }^{1}$ \\ ${ }^{1}$ Department of Surgical Sciences, Dentistry, Gynecology and Pediatrics, ${ }^{2}$ Section of Clinical Biochemistry, University of Verona, Verona, Italy; \\ ${ }^{3}$ Medical School of Tongji University, Shanghai 200072, China \\ Contributions: (I) Conception and design: M Zaffanello, G Piacentini; (II) Administrative support: None; (III) Provision of study materials or patients: \\ None; (IV) Collection and assembly of data: M Zaffanello, M Piazza, L Tenero; (V) Data analysis and interpretation: M Zaffanello, G Piacentini; (VI) \\ Manuscript writing: All authors; (VII) Final approval of manuscript: All authors. \\ Correspondence to: Marco Zaffanello, MD. Department of Surgical Sciences, Dentistry, Gynecology and Pediatrics, Pediatric Division, University of \\ Verona, Verona, Italy. Email: marco.zaffanello@univr.it.
}

\begin{abstract}
Background: Sleep-disordered breathing (SDB) is a general term encompassing a variety of breathing problems occurring during the sleep and characterized by frequently reported signs such as sleep apneas and snoring. Published studies on this topic are increasing over time, as demonstrated by the number of papers available on on-line databases.

Methods: Google Trends is a freely accessible and reliable online portal, which allows to explore internet search data. Due to the focus on of childhood SDB in published research, and because of its impact on health and wellbeing, this original study aims at investigating the worldwide popularity of most common sleep signs (apnea and snoring) from January 1st, 2004 to present time.

Results: The trend of interest for 'sleep', 'sleep apneas' and 'snoring' limited to pediatric age was lower than its overall popularity in the general population, thus reflecting a lower interest of these symptoms in children than in adults. Unlike an increasing trend of ongoing research, the popularity of pediatric sleep apnea and snoring was found to be relatively low around the world, and remained fairly stable over time.

Conclusions: This is a matter for concern, since the low popularity of SDB in children is counterbalanced by a need for reinforcing educational programs aimed at increasing widespread awareness, diagnosis and management of this condition.
\end{abstract}

Keywords: Children; Google Trends; sleep apnea; sleep disordered breathing; snoring; pediatric; polysomnography (PSG)

Submitted Jan 29, 2019. Accepted for publication Mar 29, 2019.

doi: $10.21037 /$ tp. 2019.03 .04

View this article at: http://dx.doi.org/10.21037/tp.2019.03.04

\section{Introduction}

Sleep-disordered breathing (SDB) is a general clinical term devised to gather a number of wide-ranging breathing problems occurring during sleep. For example, obstructive sleep apnea syndrome (OSAS) in children is defined as a disorder of breathing during sleep, characterized by prolonged partial upper airway obstruction and/or intermittent complete obstruction (obstructive apnea) which disrupts normal ventilation during sleep and normal sleep patterns (1). Frequently reported symptoms are sleep apneas and snoring.

Childhood SDB symptoms may include multiple phenotypes depending on craniofacial anatomy, tonsil and adenoid dimensions, bodily habitus and rhinitis symptoms. Rather than being considered a homogenous disorder, SDB may hence include multiple overlapping phenotypes, each characterized by virtually unique risk factors (2). Obese children display higher prevalence and severity of OSA (3). Notably, craniofacial disharmony in skeletal diseases 


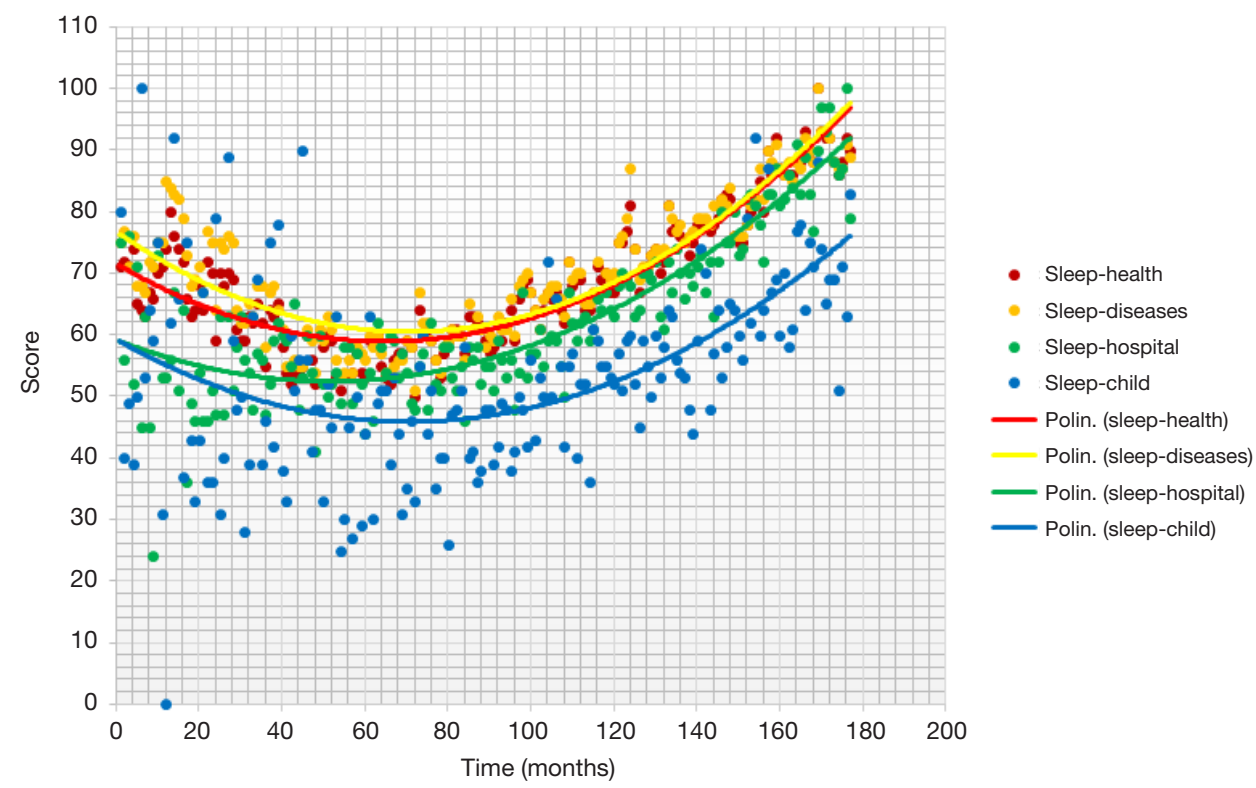

Figure 1 Distribution by time of interest (months; month 0 corresponds to January 1st, 2004) for sleep (score) using the search criterion "health", "disease", "hospital and sanitary services" and "paediatrics". Fit lines described polynomial grade 2 trend.

is associated with $\operatorname{SDB}(4,5)$ and the prevalence of this problem in children has been shown to be worryingly high $(5,6)$.

The American Academy of Pediatrics has published guidelines for diagnosis and management of OSAS, in 2002 (7). Since overnight polysomnography (PSG) remains the gold standard for diagnosing OSAS, diagnostic efficiency largely depends on availability and accessibility of this technique. Earlier observations supported the validity of domiciliary respiratory polygraphy (RP) in children with history and physical examination suggestive of OSAS (8). The combined use of sleep clinical record score and nocturnal oximetry has moderate success in predicting SDB severity when PSG testing is not a choice (9).

Recent evidence attests that the number of published studies on SDB is steadily increasing over time, as demonstrated by a search on two biomedical on-line databases (PubMed and Scopus) using the search terms 'sleep apnea' and 'children' (Figure 1).

Google Trends is a freely accessible and reliable online portal, which allows to explore Internet search data. Due to the focus on childhood SDB in published research, and because of its impact on health and wellbeing, we hence planned an original study aimed at investigating the worldwide popularity of the most common sleep signs (i.e., apnea and snoring) in paediatrics.

\section{Methods}

Two electronic searches were carried out in Google Trends, using the keywords 'sleep' AND 'sleep apnea', and 'sleep' AND 'snoring' respectively (10), by the search criterion 'health', 'diseases', 'hospital and sanitary services' and 'pediatric'. Language limitation included English only and searches were performed from the first date available in Google Trends (i.e., January 1st, 2004) to the present time (i.e., September $22^{\text {nd }}, 2018$ ). As for the Google Trends algorithm, results were then combined and scaled according to the peak of popularity (i.e., a value of 100) recorded throughout the search period. Data were tabulated in Microsoft ${ }^{\circledR}$ Excel Software and Kolmogorov-Smirnov test was performed to explore normality of distribution.

Descriptive statistics as mean and standard deviation (SD) were used as well as a non-parametric test for coupled variables was performed to explore differences between scores of the same categories ('sleep' or 'sleep apneas' or 'snoring') resulting from different search criterion ('health', 'diseases', 'hospital and sanitary services' and 'pediatric').

Spearman correlation assisted in exploring possible correlations between the keywords scores in paediatrics against the search terms criteria.

SPSS 22.0 statistics software for Windows provided the statistical analysis. The study was conducted in accordance with the guidelines of the Declaration of Helsinki and 
Table 1 Descriptive statistics

\begin{tabular}{lcccc}
\hline Search criterion variables & Health & Diseases & Hospital and sanitary services & Pediatrics \\
\hline Sleep & $67.0(66.86-70.15)$ & $69.0(68.50-71.77)$ & $59.0(60.55-64.39)$ & $53.0(51.45-55.98)$ \\
Sleep apneas & $10.0(10.74-11.22)$ & $13.0(13.85-14.58)$ & $4.0(4.09-4.58)$ & $1.0(1.74-3.27)$ \\
Snoring & $7.0(7.20-7.61)$ & $10.0(10.23-10.82)$ & $2.0(1.72-2.10)$ & $0(0.64-1.47)$ \\
\hline
\end{tabular}

Values are shown as median and $95 \% \mathrm{Cl}$.

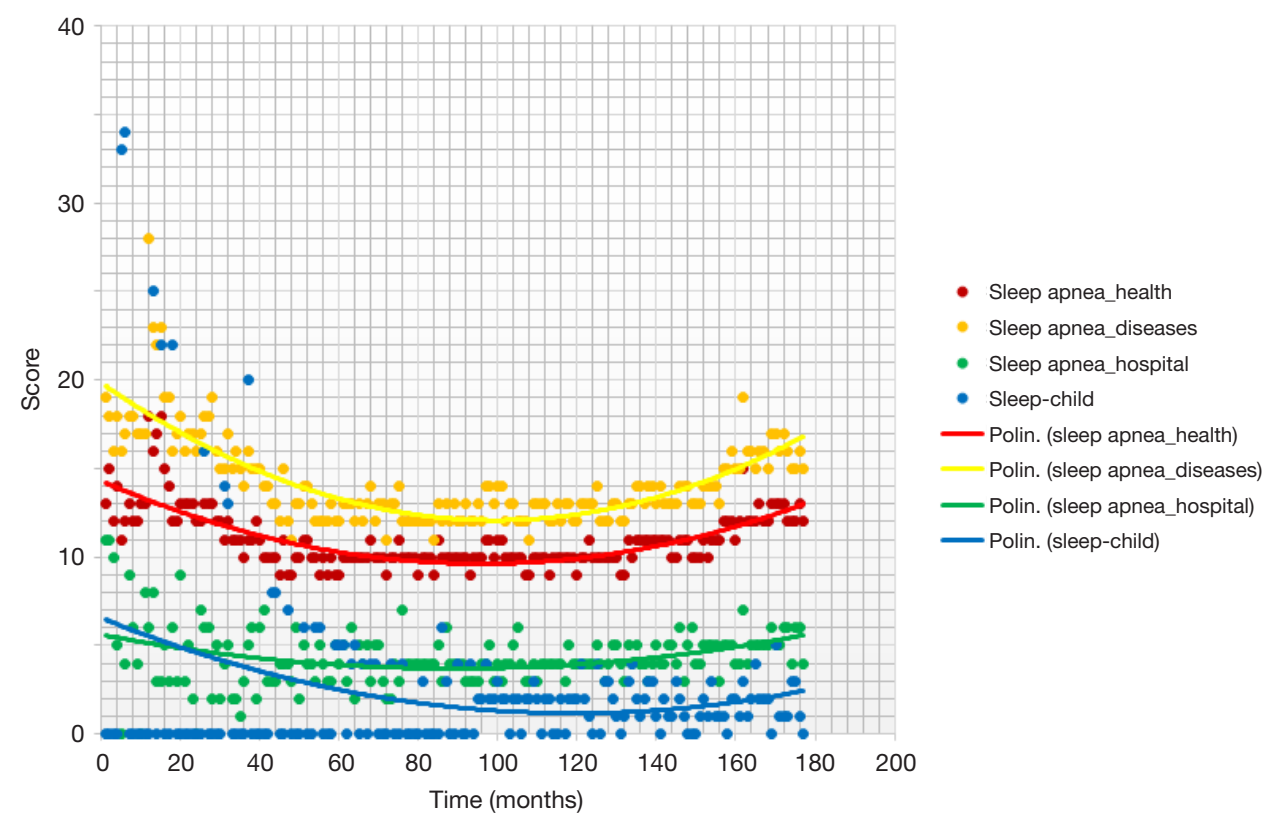

Figure 2 Distribution by time of interest (months; month 0 corresponds to January 1st, 2004) for sleep apneas (score) using the search criterion "health", "disease", "hospital and sanitary services" and "paediatrics". Fit lines described polynomial grade 2 trend.

under the terms of relevant local legislation.

\section{Results}

Descriptive statistics (median and 95\% CI) of the keywords 'sleep', 'sleep apnea' and 'snoring' resulting from the four criteria is shown in Table 1.

Whilst the Google Trends score for 'sleep' and 'sleep apnea' using 'pediatric' criteria were not normally distributed, the key word 'sleep' coupled with the search criterion "paediatrics" $(\mathrm{P}=0.20)$ was normally distributed.

Figures 2,3 show the distribution over time of Google searches interest for sleep (score) and sleep apneas (score) respectively, using all four search criteria. Finally, Figure 4 shows the distribution over time of searches for snoring (score) using the same search criteria. All lines in the figures represent polynomial grade 2 equations.
Furthermore, Table 2 shows the non-parametric test between sleep, sleep apneas and snoring scores related to the search criteria. A statistically significant difference is apparent in the value of these variables. In particular, the trend of popularity of the keywords "sleep", "sleep apneas" and "snoring" limited to pediatric age was significantly lower than that in the general population, thus suggesting that the online relative interest exercised on Google Searches is much lower in children than in adults.

Table 3 shows Spearman's correlation analysis among "sleep", "sleep apneas" and "snoring" score in pediatrics with others search criteria. Sleep score in pediatrics was positively correlated with others search criteria. On the contrary, "sleep apneas" and "snoring" score in paediatrics did not correlate with other search criteria, with only exception of the correlation between snoring and "hospital and sanitary service". Notably, this last correlation was 


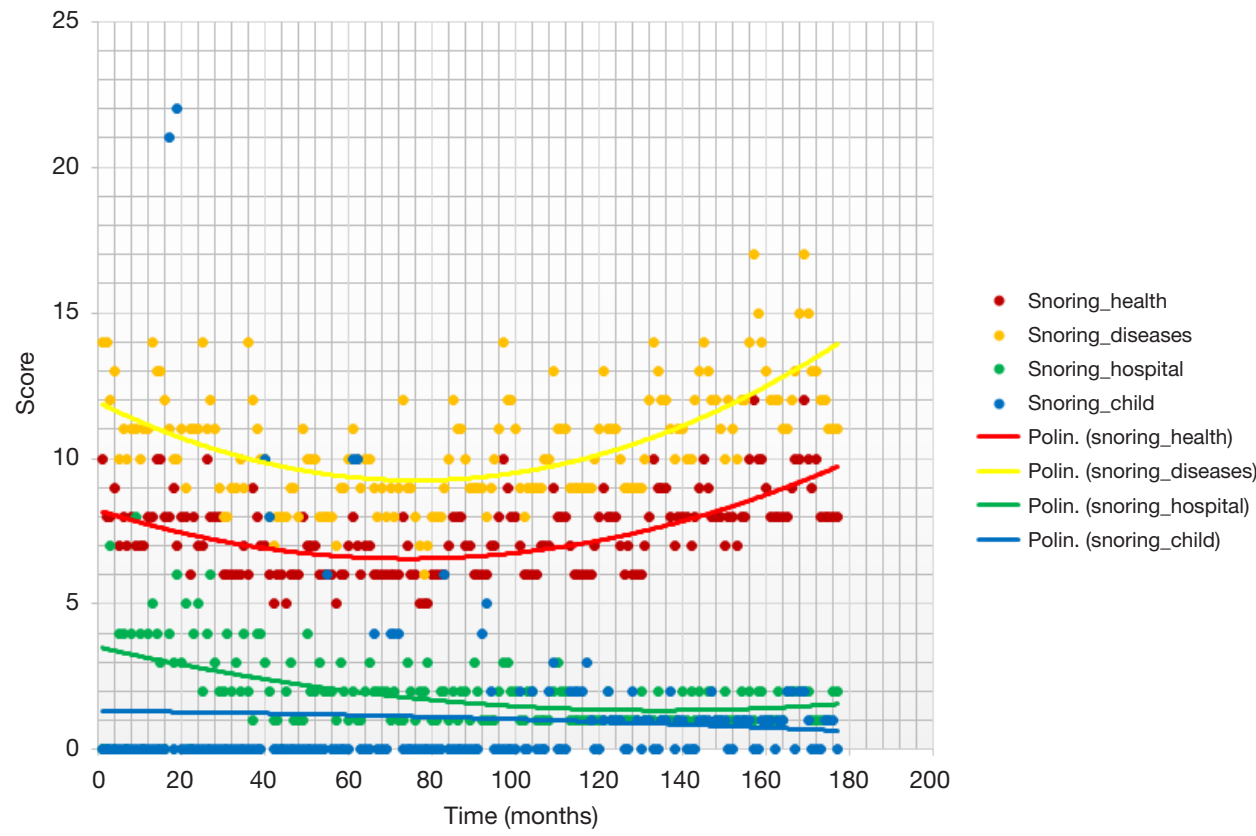

Figure 3 Distribution by time of interest (months; month 0 corresponds to January 1st, 2004) for snoring (score) using the search criterion "health", "disease", "hospital and sanitary services" and "paediatrics". Fit lines described polynomial grade 2 trend.

Number of publications

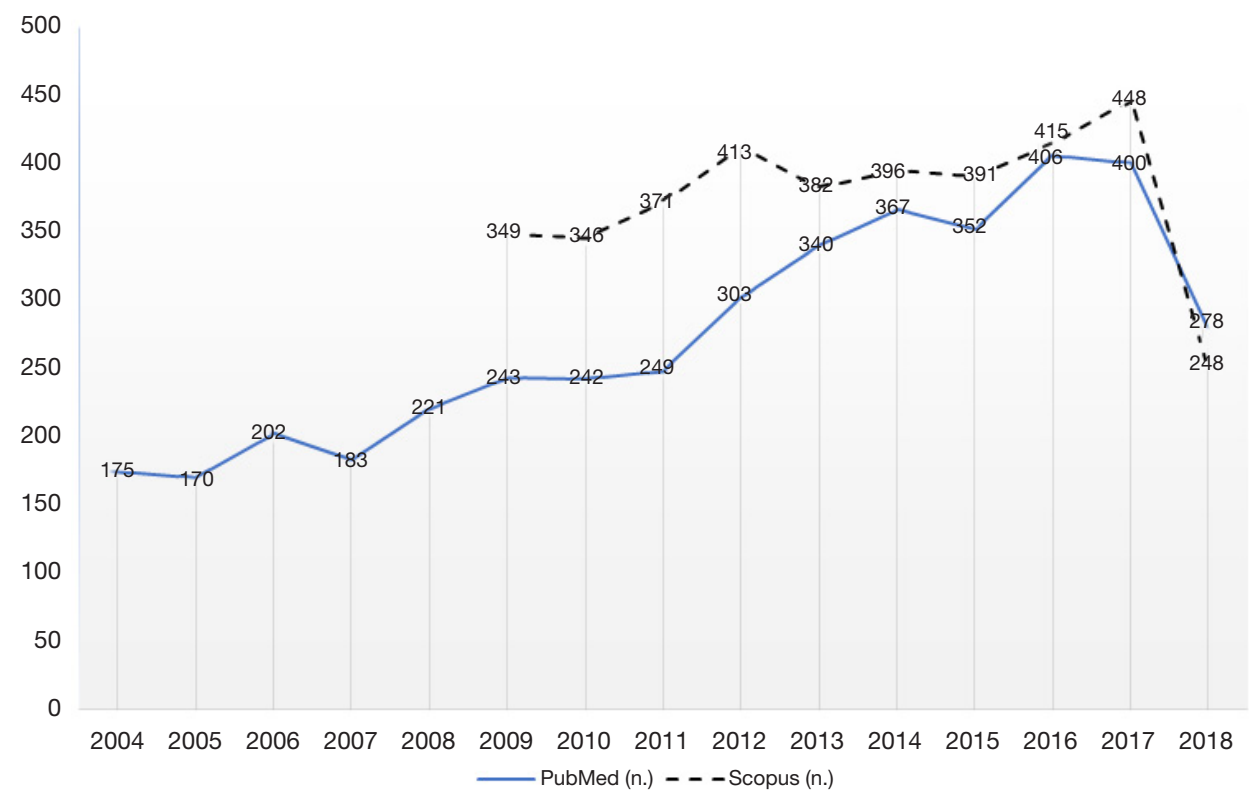

Figure 4 Number of publications by year available using the principal online databases (PubMed and Scopus). 
Table 2 Non parametric test for coupled variables between Google Trends scores (sleep, sleep apneas, snoring) available in "pediatric" domain versus scores of "health", "disease" and "hospital and sanitary service" domains

\begin{tabular}{|c|c|c|c|}
\hline \multirow{2}{*}{ Domain } & \multicolumn{3}{|c|}{ Pediatrics } \\
\hline & Sleep & Sleep apneas & Snoring \\
\hline \multicolumn{4}{|l|}{ Sleep } \\
\hline Health & $P<0.001$ & & \\
\hline Disease & $P<0.001$ & & \\
\hline $\begin{array}{l}\text { Hospital and sanitary } \\
\text { services }\end{array}$ & $P<0.001$ & & \\
\hline \multicolumn{4}{|l|}{ Sleep apneas } \\
\hline Health & & $P<0.001$ & \\
\hline Disease & & $P<0.001$ & \\
\hline $\begin{array}{l}\text { Hospital and sanitary } \\
\text { services }\end{array}$ & & $P<0.001$ & \\
\hline \multicolumn{4}{|l|}{ Snoring } \\
\hline Health & & & $P<0.001$ \\
\hline Disease & & & $P<0.001$ \\
\hline $\begin{array}{l}\text { Hospital and sanitary } \\
\text { services }\end{array}$ & & & $P<0.001$ \\
\hline
\end{tabular}

negative, thus suggesting a relatively low interest for this symptom combined with "hospital and health services" as search criterion.

Figure 5 shows the scores of popularity of "sleep apneas" around the world associated with "sleep disorder" (Figure 5A). Interestingly, US, Canada and Australia appear at the top of the list by number of searches grouped by country. Conversely, the same data show that in terms of popularity, Canada and US appear at the bottom of list for number of searches by country for "sleep apneas" around the world coupled with "pediatric" (Figure 5B).

\section{Discussion}

Recent meta-analysis of published studies which calculated an overall prevalence of habitual snoring of $7.5 \%$ (95\% CI: $5.8-9.6 \%$ ) in childhood, leaves experts in no doubt that SDB is a silent epidemic in the pediatric population (11). Owing to frequency and morbidity, several official or evidence-based guidelines now recommend screening, monitoring and treating OSA in the pediatric population $(1,12,13)$. Albeit the prevalence of OSAS (OSAS) seemingly ranges between
Table 3 Spearman correlation analysis (two tails) between Google Trends scores (sleep, sleep apneas, snoring) available in "pediatric" domain versus scores of "health", "disease" and "hospital and sanitary service" domains

\begin{tabular}{|c|c|c|c|}
\hline \multirow{2}{*}{ Conditions } & \multicolumn{3}{|c|}{ Pediatrics } \\
\hline & Sleep & Sleep apneas & Snoring \\
\hline \multicolumn{4}{|l|}{ Sleep } \\
\hline Health & $\begin{array}{c}r=0.565 \\
(P<0.001)\end{array}$ & & \\
\hline Disease & $\begin{array}{c}r=0.552 \\
(P<0.001)\end{array}$ & & \\
\hline $\begin{array}{l}\text { Hospital and } \\
\text { sanitary services }\end{array}$ & $\begin{array}{c}r=0.550 \\
(P<0.001)\end{array}$ & & \\
\hline \multicolumn{4}{|l|}{ Sleep apneas } \\
\hline Health & & $\begin{array}{c}r=-0.078 \\
(P=N S)\end{array}$ & \\
\hline Disease & & $\begin{array}{c}r=-0.094 \\
(P=N S)\end{array}$ & \\
\hline $\begin{array}{l}\text { Hospital and } \\
\text { sanitary services }\end{array}$ & & $\begin{array}{l}r=0.072 \\
(P=N S)\end{array}$ & \\
\hline \multicolumn{4}{|l|}{ Snoring } \\
\hline Health & & & $\begin{array}{l}r=0.055 \\
(P=N S)\end{array}$ \\
\hline Disease & & & $\begin{array}{l}r=0.052 \\
(P=N S)\end{array}$ \\
\hline $\begin{array}{l}\text { Hospital and } \\
\text { sanitary services }\end{array}$ & & & $\begin{array}{l}r=-0.169 \\
(P<0.05)\end{array}$ \\
\hline
\end{tabular}

$0.1 \%$ and $13 \%$, most studies reported a peak frequency comprised between $1-5 \%(1,11)$, which makes it a relatively common disease that most clinicians are likely to encounter in primary practice (1). In 2016, 3.95 million births were reported in the US (https://www.cdc.gov/nchs/data/nvsr/ nvsr67/nvsr67_01.pdf) whilst 473,438 births were recorded in the Italian Resident Population Register (ISTAT, https:// www.istat.it/en/archivio/206609). This set of data would lead to estimate that the predictable number of children who are likely to develop OSAS later in life is approximately are 39,500 in the US and 4,730 in Italy, respectively.

Sleep apnea in children may develop with subtle and often overlooked symptoms, thus imposing larger diagnostic challenges than in adults and necessitating more thorough investigations. Children may have resistance to morning waking, be more irritable, have trouble paying attention at school, or even be overactive during the day. 

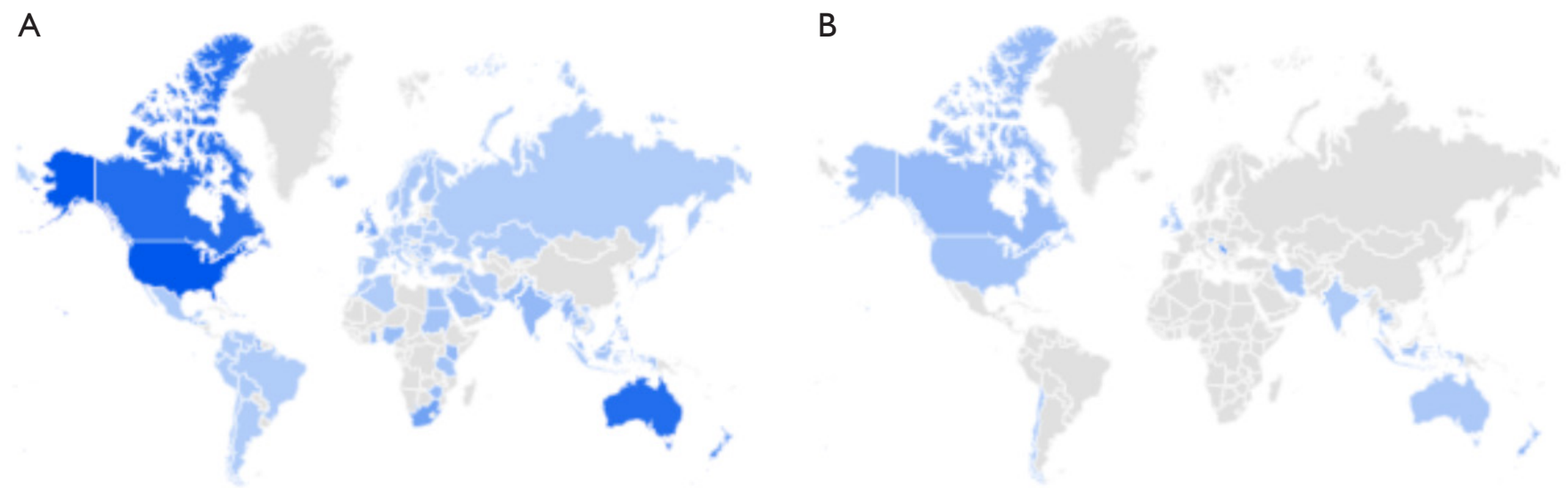

Figure 5 Geographical distribution of web searches recorded by Google Trends from January 1st, 2004. (A) Interest for "sleep apnea" in using criterion "sleep disorder" (best scores: US =100, Australia and Canada =81); (B) interest for "sleep apnea" in using criterion "pediatric" (best scores: Bahrain =100, Serbia $=61$, New Zealand $=18$, Canada $=16$ and US $=8$ ).

Many studies showed the benefits of early management on this condition on many behavioural, neurologic and medical domains (14-17). The treatment of OSA may be both medical and surgical. Although OSAS seems to be improved postoperatively, the rate of patients with residual OSAS ranges between $13 \%$ and $29 \%$ in low-risk populations, up to $73 \%$ in studies in obese children and in those applying more stringent PSG diagnostic criteria (18).

Google Trends is a free web tools based exclusively on Google searches, which then generates geographical and temporal information on specific search terms (19). Recent evidence suggests that the use of Google Trends may be of value in healthcare, since it may allow to garner important information on disease epidemics and population health. It essentially mirrors the public interest in a certain argument, whose final score may also be influenced by media clamor $(20,21)$.

To the best of our knowledge although Google Trends has also been used in pediatrics before, no reliable information concerning this practice has been published on childhood respiration thus far. Google Trends search trends have been shown to reliably mirror real-life epidemiology of certain diseases, e.g., allergic rhinitis. More specifically, different search terms were found to display a clear seasonality trend (e.g., "hay fever", "allergy", "pollen") (22). Interestingly, a previous study exploring the popularity of OSAS (i.e., by using the search terms "snoring" and "sleep apnea") in US and Australia, showed a significant seasonal pattern of such searches, with a clear peak in the winter and early spring (10).
The most interesting finding emerged from the present analysis is that the popularity of "sleep apnea" (Figure 5) and "snoring" was lower in pediatrics than in the general population, even using the "heath and sanitary service" search criterion. Albeit the overall popularity of "sleep" and "childhood sleep" appeared comparable, that of sleep apnea and snoring did not correlate with the same variable (sleep apnea and snoring) related to childhood. These findings do not appear aligned with the interest from international scientific community, as attested by the relative number of publications available in PubMed and Scopus online databases (Figure 1).

The different popularity of sleep apnea and snoring in adults and children deserves further scrutiny. In adult populations the popularity for SDB has consistently increased by time, mainly due to legislative acts and enforcement thereof on the roads, work place etc. For example, on $1^{\text {st }}$ July 2014, the European Union has approved a new directive on issuing and renewing driving licenses, introducing important limitations for patients suffering from nocturnal sleep apnea. In short, the directive fully acknowledges and ratifies the importance of recognizing chronic pathologies such as OSAS, mandating medical consultation while obtaining or renewing the driving license. It is mandatory in all States and Territories in Australia to report health conditions that may impair driving ability, also including sleep disorders. Alas, no official guidance on screening and/or diagnosing OSAS before obtaining or renewing the dive licence has been issued by the US Federal Motor Carrier Safety Administration (FMCSA). 
With regards to the children population, there appears to be a sort of neglectful attitude by the clinical community, which is reflected by the exponentially scarce mention both in legal literature and in the media. Sadly, alongside other sleep problems in children, SDB continues to be underrecognised by clinicians in both primary and secondary care. Encouragingly, some circumscribed awareness campaigns were successful to enhance the parental knowledge of this condition in the short-term, but the effects did not last for long on follow-up (23).

\section{Conclusions}

The results of this analysis suggest that, if on the one hand there is as steady trend of ongoing research on the topic for the adults' population, the popularity of pediatric "sleep apnea" and "snoring" remains low around the world, and consistently so over time. This is serious cause for concern, since the low popularity of SDB in children is by default a call for action in terms of educational programs aimed at increasing widespread awareness, diagnosis and management of this condition among clinicians and the wider public.

\section{Acknowledgments}

None.

\section{Footnote}

Conflicts of Interest: The authors have no conflicts of interest to declare.

\section{References}

1. Marcus CL, Brooks LJ, Draper KA, et al. Diagnosis and management of childhood obstructive sleep apnea syndrome. Pediatrics 2012;130:576-84.

2. Kamal M, Tamana SK, Smithson L, et al. Phenotypes of sleep-disordered breathing symptoms to two years of age based on age of onset and duration of symptoms. Sleep Med 2018;48:93-100.

3. Su MS, Zhang HL, Cai XH, et al. Obesity in children with different risk factors for obstructive sleep apnea: a community-based study. Eur J Pediatr 2016;175:211-20.

4. Zaffanello M, Piacentini G, Sacchetto L, et al. SleepDisordered Breathing in Children with Rare Skeletal Disorders: A Survey of Clinical Records. Med Princ Pract
2018;27:451-8.

5. Zaffanello M, Antoniazzi F, Tenero L, et al. Sleepdisordered breathing in paediatric setting: existing and upcoming of the genetic disorders. Ann Transl Med 2018;6:343.

6. Bixler EO, Vgontzas AN, Lin HM, et al. Sleep disordered breathing in children in a general population sample: prevalence and risk factors. Sleep 2009;32:731-6.

7. Clinical practice guideline: diagnosis and management of childhood obstructive sleep apnea syndrome. Pediatrics 2002;109:704-12.

8. Alonso-Álvarez ML, Terán-Santos J, Ordax Carbajo E, et al. Reliability of home respiratory polygraphy for the diagnosis of sleep apnea in children. Chest 2015;147:1020-8.

9. Villa MP, Pietropaoli N, Supino MC, et al. Diagnosis of Pediatric Obstructive Sleep Apnea Syndrome in Settings With Limited Resources. JAMA Otolaryngol Head Neck Surg 2015;141:990-6.

10. Kaditis AG, Alonso Alvarez ML, Boudewyns A, et al. Obstructive sleep disordered breathing in 2- to 18-yearold children: diagnosis and management. Eur Respir J 2016;47:69-94.

11. Ingram DG, Matthews CK, Plante DT. Seasonal trends in sleep-disordered breathing: evidence from Internet search engine query data. Sleep and Breathing 2015;19:79-84.

12. Lumeng JC, Chervin RD. Epidemiology of pediatric obstructive sleep apnea. Proc Am Thorac Soc 2008;5:242-52.

13. Roland PS, Rosenfeld RM, Brooks LJ, et al. Clinical practice guideline: Polysomnography for sleep-disordered breathing prior to tonsillectomy in children. Otolaryngol Head Neck Surg 2011;145:S1-15.

14. Trosman I. Childhood obstructive sleep apnea syndrome: a review of the 2012 American Academy of Pediatrics guidelines. Pediatr Ann 2013;42:195-9.

15. Kansagra S, Vaughn B. Pediatric sleep apnea: Five things you might not know. Neurol Clin Pract 2013;3:321-5.

16. Tagetti A, Bonafini S, Zaffanello M, et al. Sleepdisordered breathing is associated with blood pressure and carotid arterial stiffness in obese children. J Hypertens 2017;35:125-31.

17. Zaffanello M, Piacentini G, Pietrobelli A, et al. Ambulatory clinical parameters and sleep respiratory events in a group of obese children unselected for respiratory problems. World J Pediatr 2017;13:577-83.

18. Marcus CL, Brooks LJ, Draper KA, et al. Diagnosis and management of childhood obstructive sleep apnea 
syndrome. Pediatrics 2012;130:e714-55.

19. Seidl S, Schuster B, Ruth M, et al. What Do Germans Want to Know About Skin Cancer? A Nationwide Google Search Analysis From 2013 to 2017. J Med Internet Res 2018;20:e10327.

20. Cervellin G, Comelli I, Lippi G. Is Google Trends a reliable tool for digital epidemiology? Insights from different clinical settings. J Epidemiol Glob Health 2017;7:185-9.

21. Mahroum N, Bragazzi NL, Brigo F, et al. Capturing public interest toward new tools for controlling human immunodeficiency virus (HIV) infection exploiting data from Google Trends. Health Informatics J 2019;25:1383-97.

22. Bousquet J, Agache I, Anto JM, et al. Google Trends terms reporting rhinitis and related topics differ in European countries. Allergy 2017;72:1261-6.

23. McDowall PS, Galland BC, Campbell AJ, et al. Parent knowledge of children's sleep: A systematic review. Sleep Med Rev 2017;31:39-47.
Cite this article as: Zaffanello M, Lippi G, Arman N, Piazza M, Tenero L, Piacentini G. Popularity of sleep disordered breathing in childhood: an analysis of worldwide search using Google Trends. Transl Pediatr 2019;8(5):383-390. doi: 10.21037/tp.2019.03.04 